\title{
Fermented Soybean with Thrombosis Preventing Activity Using Mushroom Mycelia as Microbial Source
}

\author{
Tokumitsu OKamura-Matsui, Hiromi IZUTA, Tomomi TomodA, Hiroko NodA, Shoko FuKudA and Masahiro OHsugi \\ Department of Food Science and Nutrition, School of Human Environmental Sciences, Mukogawa Women's University, 6-46 Ikebiraki-cho \\ Nishinomiya, Hyogo, 663-8137, Japan
}

Received September 11, 2002; Accepted May 15, 2003

\begin{abstract}
Bacillus natto is the main microorganism used to make natto (fermented soybeans), because this microbe has good ability to produce protease. However, it is known that some genera of mushroom also produce protease, and in this study we made a fermented soybean using a mushroom mycelia in place of $\boldsymbol{B}$. natto. We found that the fermented soybean made using mycelia of Flammulina velutipes and Roseofomes subflexibilis showed a thrombosis preventing activity: a prolonged thrombin clotting time 8.2 fold that of control.
\end{abstract}

Keywords: fermented soybean, mushroom mycelia, anti-thrombin substance, thrombosis

Natto (fermented soybeans) is a traditional fermented food in Japan and Bacillus natto is used to make natto because it has strong ability to produce protease (Kamata et al., 1989). Other organisms also produce protease including the mushrooms Flammulina velutipes (Arima et al., 2000), Grifola frondosa (Okamura et al., 1997a) and Pleurotus eryngii (Arima et al., 2000), which are popular in Japan. These are also rich in fiber such as glucan, protein and a precursor of vitamin D, in addition to having a preventive effect on thrombosis and cancer (Whistler et al., 1976; Hirasawa et al., 1997; Okamura et al., 1997b; Okamura et al., 2000). In this study we produced a fermented soybean with mushroom mycelia because we hypothesized it might have a preventive effect against thrombosis and cancer, as well as other health benefits. In this study, we report on the production of this fermented soybean produced with mushroom mycelia and its characteristics.

\section{Materials and Methods}

Cultivation of mushrooms Agaricus blazei MWU-C20, Flammulina velutipes MWU-C3, Grifola frondosa MWU-C9, Laetiporus sulphureus MWU-W8, Pleurotus cornucopiae var. citrinopileatus MWU-C8, Pleurotus eryngii MWU-C21 and Roseofomes subflexibilis MWU-W117 were used in this experiment because these mushrooms grow well on soybean and have anti-thrombin and fibrinolytic activities. A. blazei (dried type), $F$. velutipes, $G$. frondosa, $P$. cornucopiae var. citrinopileatus and $P$. eryngii were purchased at a local market in Nishinomiya Japan. L. sulphureus and $R$. subflexibilis were isolated from wild mushrooms in Ashibidani, Shiga and Sendai, Miyagi prefecture, Japan, and cultures were obtained by aseptic inoculation of the tissue from the fruit bodies onto a medium containing $2 \%$ malt extract (pH 5.6). A small quantity of mushroom cultures grown on an incline were inoculated into $200 \mathrm{ml}$ of the medium in a $500 \mathrm{ml}$ Erlenmeyer flask. Cultivation was carried out at $25^{\circ} \mathrm{C}$ for

E-mail: tokamura@mwu.mukogawa-u.ac.jp.
2 weeks under aerobic conditions with a rotary shaker (100 r.p.m.). The weights (fresh weight (dry weight)/200 $\mathrm{ml}$ medium) and $\mathrm{pH}$ after cultivation of $A$. blazei, F. velutipes, $G$. frondosa, $L$. sulphureus, $P$. cornucopiae var. citrinopileatus, $P$. eryngii and $R$. subflexibilis were $2.2 \mathrm{~g}(0.15 \mathrm{~g}), 1.1 \mathrm{~g}(0.02 \mathrm{~g}), 1.2 \mathrm{~g}(0.03 \mathrm{~g})$, $1.8 \mathrm{~g}(0.03 \mathrm{~g}), 1.3 \mathrm{~g}(0.08 \mathrm{~g}), 1.1 \mathrm{~g}(0.09 \mathrm{~g})$ and $2.0 \mathrm{~g}(0.10 \mathrm{~g})$, and 5.3, 5.2, 3.3, 1.7, 5.2, 6.1 and 4.8, respectively.

Mycelia prepared from each mushroom fruit body were collected by centrifugation at $10,000 \times \mathrm{g}$ for $10 \mathrm{~min}$ and washed twice with autoclaved ice-cold saline solution.

Assay for proteolytic activity The fresh mushroom mycelia (fresh weight $0.5 \mathrm{~g}$ ), suspended in $0.5 \mathrm{ml}$ of $10 \mathrm{mM}$ Tris- $\mathrm{HCl}$ buffer ( $\mathrm{pH} \mathrm{8.5)} \mathrm{or} 0.5 \mathrm{ml}$ of $10 \mathrm{mM}$ Mcllvaine buffer ( $\mathrm{pH} 5.0$ ) was subjected to sonication with an ultrasonic oscillator (BRANSON, $20 \mathrm{kHz}$ ) for $16 \mathrm{~min}$ at below $8^{\circ} \mathrm{C}$. The undestroyed cells and debris were removed by centrifugation at $10,000 \times g$ for $20 \mathrm{~min}$. The supernatant solution obtained was used as the cellfree extract.

The alkaline proteolytic activity (Tris- $\mathrm{HCl}$ buffer $(\mathrm{pH} \mathrm{8.5))}$ was assayed using the method described by Arima et al. (1967). The substrate employed for the assay of proteolytic activity was $1.2 \%$ solution of Hammersten casein (Merck, Germany). The acid proteolytic activity (McIlvaine buffer ( $\mathrm{pH}$ 5.0)) was assayed using the Anson-hemoglobin method described by Anson (1939). One unit of the enzyme was defined as the amount that catalyzed the formation of $1 \mu \mathrm{mol}$ of L-tyrosine per min in the measurement by the method of Lowry et al. (1951) with crystalline bovine serum albumin (Wako Co. Ltd., Osaka) as the standard (Fig. 1).

Fermented soybean making Fermented soybean was made by following the conventional methods except that mushroom mycelia were used in place of Bacillus natto. Briefly, $20 \mathrm{~g}$ (about $2 \mathrm{~g} /$ soybean) of soybean (Tsurunoko soybean, Hokkaido) was washed thoroughly with water and placed in a flat-bottomed tube. The beans were soaked in water overnight at room temperature, the water was drained off, and the flat-bottomed tube was 


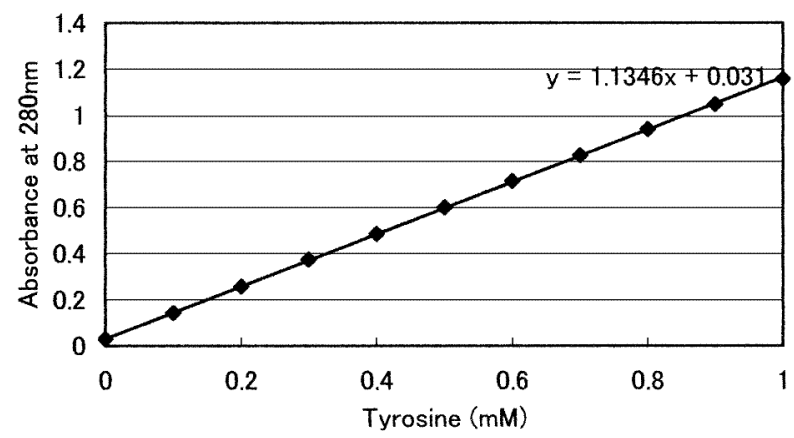

Fig. 1. Standard curve of tyrosine.

sealed with aluminum foil. After autoclaving for $30 \mathrm{~min}$ at a pressure of $1 \mathrm{~kg} / \mathrm{cm}^{2}$, the soybean was cooled and inoculated with fresh mycelia ( $1 \mathrm{~g})$, obtained by the method described in the cultivation of mushrooms, and incubated at $25^{\circ} \mathrm{C} \pm 1^{\circ} \mathrm{C}$ for 12 days. The same soybean without inoculation was prepared as a control (soybean).

Coagulability test The coagulability test was done using the thrombin time (TT): the time elapsing until the fibrin formation of thrombin, by the method described by Kinoshita and Horie (1993). Briefly, after fermentation, the fermented soybean $(1 \mathrm{~g})$, suspended in water $(4 \mathrm{ml})$, was subjected to sonication with an ultrasonic oscillator (BRANSON, $20 \mathrm{kHz}$ ) for $3 \mathrm{~min}$ at below $8^{\circ} \mathrm{C}$. The undestroyed fermented soybean and debris were discarded by centrifugation at $10,000 \times g$ for $10 \mathrm{~min}$, and the supernatant was applied for determining thrombin activity. Bovine $\alpha-$ thrombin was purchased from Mochida Phamaceutical Co., Ltd.. The thrombin clotting time in a reaction mixture $\left(37^{\circ} \mathrm{C}\right)$ containing $50 \mu \mathrm{l}$ of the supernatant, $50 \mu \mathrm{l}$ of $12.5 \mathrm{NIH}$ unit/ml thrombin and $200 \mu \mathrm{l}$ of $0.33 \%$ bovine fibrinogen was measured using a $\mathrm{KC1A}$ coagulometer (Henrich Amelung).

Fibrinolytic activity test The method of Astrup and Mullertz (1952) using fibrin plates was employed to determine fibrinolytic activities. Briefly, $30 \mu \mathrm{l}$ of the supernatant, obtained by the method described in the coagulability test was used, an artificial thrombus was prepared in a disk by coagulating $0.4 \%$ bovine fibrinogen using thrombin, and the potency required to dissolve the thrombus was determined.

\section{Results and Discussion}

As shown in Table 1, the proteolytic activities on $\mathrm{pH} 8.5$ and
pH 5.0 of A. blazei, F. velutipes, G. frondosa, L. sulphureus, $P$. cornucopiae var. citrinopileatus, $P$. eryngii, $R$. subflexibilis and $B$. natto were 3.8, 0.01, 2.3, 6.8, 10.8, 0.06, 0.1 and 5.6 units ( $\mu \mathrm{mol} /$ $\mathrm{mg} / \mathrm{min}$ ) and $3.5,0.1,1.8,0.7,1.5,2.5,0.4$ and 0.5 units ( $\mu \mathrm{mol} /$ $\mathrm{mg} / \mathrm{min}$ ), respectively.

The fermented soybeans produced using mushrooms are shown in Fig. 2; their hardness and flavor was soft and the original flavor, respectively.

The effects of fermented soybean produced using mushroom mycelia on thrombin time (TT) are summarized in Table 1. All six soybeans produced using mycelia of $F$. velutipes, $G$. frondosa, L. sulphureus, $P$. cornucopiae var. citrinopileatus, $P$. eryngii and $R$. subflexibilis showed anti-coagulative activities on TT, with the TT of fermented soybeans produced by mycelia of $F$. velutipes and $R$. subflexibilis being longer than that of the other mushrooms, and the thrombin clotting times more than 8.2 times longer than that of the control (soybean).

Figure 3 shows the fibrinolytic activities of fermented soybean produced using mushroom mycelia on a fibrin plate. Table 1 shows the fibrinolytic activities of the extract solution of the soybean produced using mushroom: the fermented soybean produced using $R$. subflexibilis and $P$. cornucopiae var. citrinopileatus showed high fibrinolytic activities on the fibrin plate, while the control did not.

Based on these findings we theorized that fermented soybean produced using mycelia of these mushrooms may have a preventive effect on thrombosis (Okamura et al., 2000), and that it may also contain $\beta$-D-glucan, because mycelia of mushrooms contain $\beta$-D-glucan and this is known to have a preventive effect against cancer (Whistler et al., 1976).

In general, $B$. natto is used to make natto (fermented soybeans), because this microbe has a potent ability to produce protease. On the other hand, the activities on $\mathrm{pH} 8.5$ and $\mathrm{pH} 5.0$ of A. blazei, F. velutipes, $G$. frondosa, L. sulphureus, P. cornucopiae var. citrinopileatus, $P$. eryngii and $R$. subflexibilis are almost 0.01 to 11 units $(\mu \mathrm{mol} / \mathrm{mg} / \mathrm{min}$ ) and 0.1 to 3.5 units $(\mu \mathrm{mol} / \mathrm{mg} / \mathrm{min}$ ), respectively. The activities on $\mathrm{pH} 8.5$ and $\mathrm{pH} 5.0$ of $B$. natto are 5.6 units $(\mu \mathrm{mol} / \mathrm{mg} / \mathrm{min})$ and 0.5 units $(\mu \mathrm{mol} / \mathrm{mg} / \mathrm{min})$, respectively. The proteolytic activities of $P$. cornucopiae var. citrinopileatus and $L$. sulphureus were higher than that of $B$. natto on $\mathrm{pH}$ 8.5. Further, those of most mushrooms were higher than that of $B$. natto on $\mathrm{pH}$.0.

Terashita et al. (1984) reported that the carboxy proteinase from Lentinus edodes fruit-bodies was most active between $\mathrm{pH}$

Table 1. Proteolytic activities of mushroom mycelia, and thrombin time, fibrinolytic activities and final pH of the fermented soybeans.

\begin{tabular}{|c|c|c|c|c|c|}
\hline \multirow{2}{*}{ Mushroom mycelia used } & \multicolumn{2}{|c|}{ Proteolytic activity $\left(\right.$ unit $^{a)}$ ) } & \multirow{2}{*}{ Thrombin time (s) } & \multirow{2}{*}{ Fibrinolytic activity $\left(\mathrm{mm}^{2}\right)$} & \multirow{2}{*}{ Final $\mathrm{pH}$} \\
\hline & $\mathrm{pH} 5.0$ & $\mathrm{pH} 8.5$ & & & \\
\hline Agaricus blazei & 3.5 & 3.8 & $73.6 \pm 0.3$ & $35 \pm 1$ & 8.5 \\
\hline Flammulina velutipes & 0.1 & 0.01 & $600^{c}$ & $132 \pm 2$ & 8.8 \\
\hline Grifola frondosa & 1.8 & 2.3 & $100.1 \pm 0.4$ & $42 \pm 1$ & 6.1 \\
\hline Laetiporus sulphureus & 0.7 & 6.8 & $173.7 \pm 0.5$ & $36 \pm 1$ & 8.0 \\
\hline Pleurotus cornucopiae var. citrinopileatus & 1.5 & 10.8 & $160.6 \pm 0.4$ & $288 \pm 3$ & 7.8 \\
\hline Pleurotus eryngii & 2.5 & 0.06 & $179.6 \pm 0.5$ & $63 \pm 1$ & 5.9 \\
\hline Roseofomes subflexibilis & 0.4 & 0.1 & $600^{c}$ & $500 \pm 3$ & 8.4 \\
\hline Bacillus natto & 0.5 & 5.6 & - & - & 8.3 \\
\hline Control $^{b)}$ & 0 & 0 & $73.6 \pm 0.4$ & $16 \pm 1$ & 6.4 \\
\hline
\end{tabular}

a) $\mu \mathrm{mol} / \mathrm{mg}$ (protein)/min

b) soybean

${ }^{c)}$ more than $600 \mathrm{~s}$ 

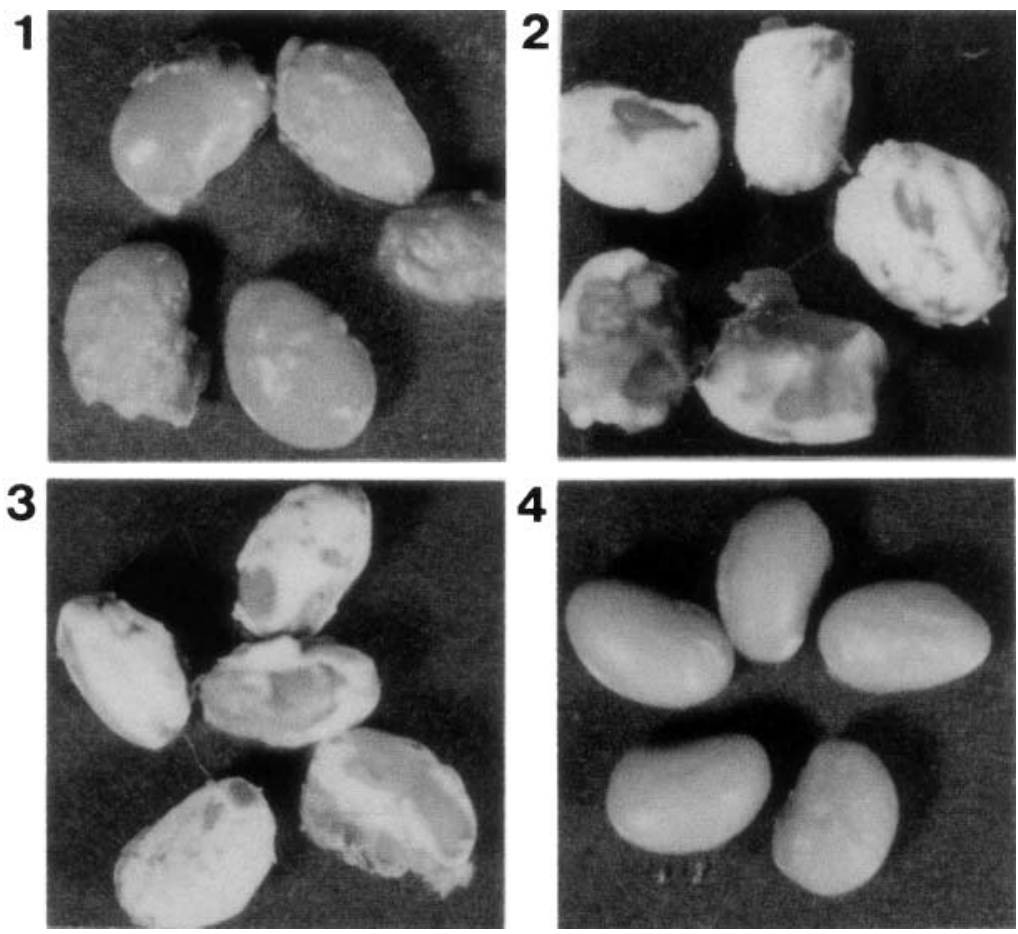

Fig. 2. Fermented soybean produced using mushrooms mycelia. 1, A. blazei; 2, F. velutipes; $3, R$. subflexibilis; 4, Control (soybean).

2.5-2.8, and stable over a range of $\mathrm{pH} 3.1-5.7$. However, final $\mathrm{pH}$ of the fermented soybean was not low value such as 2.5-2.8. Also, Terashita et al. (1981) reported that the optimal $\mathrm{pH}$ of intracellular proteinase in the mycelium was $\mathrm{pH} 2.7$ and 7.0, and when Streptomyces-pepsin inhibitor (S-PI) was added to the culture medium, the activities were strikingly changed; the carboxyl proteinase activity was remarkably decreased, while the metal proteinase activity was increased to 1.5 times that of the control (Terashita et al., 1981).

Therefore, the proteinase activity may be different from fruit body and mycelia, and may change depending on the cultural conditions. In this experiment, the mycelia of mushrooms were grown on the soybeans resulting in fermenting them.

Table 1 shows the final $\mathrm{pH}$ of the fermented soybeans. That of fermented soybeans produced by $G$. frondosa and P. eryngii was 6.1 and 5.9, respectively, while that of the soybeans produced by the other mushrooms and B. natto was $\mathrm{pH} 7.8$ to $\mathrm{pH}$ 8.8. Different fermentation by protease and the other enzymes between each mushroom and $B$. natto may produce various amino acids and organic acids, thus leading to different $\mathrm{pH}$ of the final fermented soybean product.

Kim J.H. and Kim Y.S. (1999) reported that a fibrinolytic metalloprotease has been purified from the fruiting bodies of the edible honey mushroom (Armillariella mellea), and hydrolyzes fibrinogen as well as fibrin, but shows no proteolytic activity for other blood proteins such as thrombin, human albumin, bovine albumin, human $\operatorname{IgG}$, hemoglobin, or urokinase. They also reported that the optimum $\mathrm{pH}$ of the fibrinolytic activity of metalloprotease from Armillariella mellea was $\mathrm{pH} 7$ when N-Suc-AlaAla-Pro-Phe pNA was used as a substrate, indicating that it is a neutral protease. It may be a fibrinolytic metalloprotease the same as Armillariella mellea, and therefore the fermented soy-

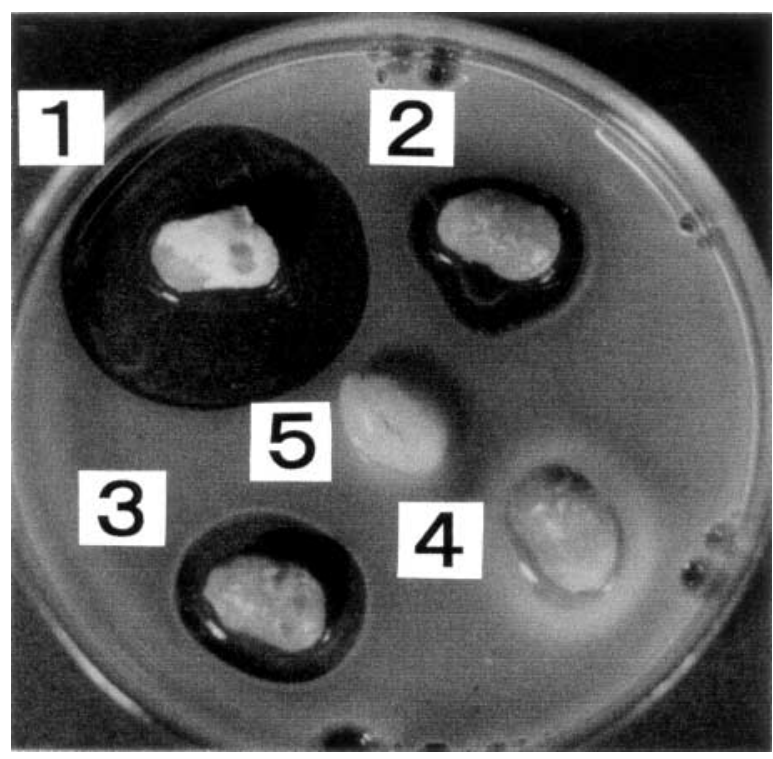

Fig. 3. Fibrinolytic activity of fermented soybean produced using mushroom mycelia. $1, R$. subflexibilis; $2, F$. velutipes; $3, P$. cornucopiae var. citrinopileatus; 4, G. frondosa; 5, Control (soybean). A dissolved zone is shown on a fibrin plate.

bean showed fibrinolytic activities.

Sumi et al. (1987) reported the presence of a strong fibrinolytic enzyme (nattokinase) in natto, and nattokinase may be an equally good protease for oral fibrinolytic therapy because of its confirmed safety for long-term intake, stability and the strong fibrinolytic activity. The fermented soybeans produced using mushroom mycelia, however, may have a preventive effect on not only thrombosis but also cancer. 
Therefore, the utilization of different fermentative microorganisms should ensure the development of new fermented foods with attractive functional and beneficial properties.

Acknowledgments This study was made possible by a grant from the Science Research Promotion Fund to Dr. Tokumitsu Okamura of Mukogawa Women's University by The Promotion and Mutual Aid Corporation for Private Schools of Japan. The authors also gratefully acknowledge a grant from Mitsukan-su Co., Ltd.

\section{References}

Anson, M.L. (1939). The estimation of pepsin, trypsin, papain, and cethepsin with hemoglobin. J. Gen. Physiol., 22, 79-89.

Arima, K., Iwasaki, S. and Tamura, G. (1967). Milk clotting enzyme from microorganisms. Agric. Biol. Chem., 31, 540-545.

Arima, S. and Suyama, K. (2000). New disease, Watakabibyo showing rot symptoms in Pleurotus eryngii caused by Cladobotryum varium. Mushroom Sci. Biotech., 8, 13-20.

Astrup, T. and Mullertz, S. (1952). The fibrin plate method for estimating fibrinolytic activity. Archs. Biochem. Biophys., 40, 346-351.

Hirasawa, R., Goto, I., Okamura, T., Horie, N., Kiyohara, T. and Ohsugi, M. (1997). Screening of fibrinolytic enzymes derived from basidiomycetes. Mushroom Sci. Biotech., 5, 13-17.

Kamata, H., Yamagata, Y., Nakamura, T., Oda, K., Murao, S. and Ichishima, E. (1989). Characterization of the complex between $\alpha_{2}$-macroglobulin and a serine proteinase from Bacillus natto. Agric. Biol. Chem., 53, 2695-2702.

Kim, J.H. and Kim, Y.S. (1999). A fibrinolytic metalloprotease from the fruiting bodies of an edible mushroom, Armillariella mellea.
Biosci. Biotechnol. Biochem., 63, 2130-2136.

Kinoshita, A. and Horie, N. (1993). Inhibitory activity of green tea catechins on thrombin. Jpn. J. Thromb. Hemost., 4, 417-422.

Lowry, H.O., Rosebrough, J.N., Farr, L.A. and Randall, J.R. (1951). Protein measurement with the folin phenol reagent. J. Biol. Chem., 193, 265-275.

Okamura, T., Nishikawa, Y., Okuda, N. and Ohsugi, M. (1997a). Effects of adding of Maitake homogenate as carbohydrate to dough on gas production in maitake bread processing. Mushroom Sci. Biotech., 5, 15-19.

Okamura, T., Horie, N., Miyazaki, Y. and Ohsugi, M. (1997b). Fumaric acid, anti-thrombin substance from Rhizopus javanicus. J. Nutr. Sci. Vitaminol, 43, 241-247.

Okamura, T., Takeno, T., Fukuda, S., Mohri, A., Noda, H., Iemoto, A., Horie, N. and Ohsugi, M. (2000). Laetiporus sulphureus, producing an anti-thrombin substance. Mushroom Sci. Biotech., 8, 119-123.

Sumi, H., Hamada, H., Tsushima, H., Mihara, H. and Muraki, H. (1987). A novel fibrinolytic enzyme (nattokinase) in the vegetable cheese Natto; a typical and popular soybean food in the Japanese diet. Experientia, 43, 1110-1111.

Terashita, T., Oda, K., Kono, M. and Murao, S. (1981). Purification and some properties of carboxyl proteinase in mycelium of Lentinus edodes. Agric. Biol. Chem., 45, 1929-1935.

Terashita, T., Oda, K., Kono, M. and Murao, S. (1984). Purification and some properties of carboxyl proteinase in extract from Lentinus edodes fruit-bodies. Agric. Biol. Chem., 48, 2639-2645.

Whistler, L.S., Bushway, A.A., Singh, P.P., Nakahara, W. and Tokuzen, R. (1976). Advances in Carbohydrate Chemistry and Biochemistry, 32, ed. by S.R. Tipson and D. Horton, Academic Press, New York, 235-275. 